\title{
Photoperiod-dependent regulation of inhibin in Siberian hamsters: II. Regulation of inhibin production and secretion by pregnant mare serum gonadotropin
}

\author{
H A Kenny ${ }^{1}$, D J Bernard ${ }^{1}$, T H Horton ${ }^{1}$ and T K Woodruff ${ }^{1,2}$ \\ ${ }^{1}$ Department of Neurobiology and Physiology, Northwestern University, Evanston, Illinois 60208, USA \\ ${ }^{2}$ Department of Medicine, Northwestern University Medical School, Chicago, Illinois 60611, USA \\ (Requests for offprints should be addressed to T K Woodruff, 2145 North Sheridan Road, OT Hogan Hall, Room 4-150, Department of Neurobiology and \\ Physiology, Northwestern University, Evanston, Illinois 60208, USA; Email; tkw@northwestern.edu) \\ (D ) Bernard is now at Population Council, New York, New York 10021, USA)
}

\begin{abstract}
Inhibin production differs in ovaries of Siberian hamsters (Phodopus sungorus) exposed to long days (LD) or short days (SD). We believe that seasonal differences in serum follicle-stimulating hormone contribute to this difference. However, given the profound photoperiodic differences in follicle maturation, serum gonadotropins alone may not account for all of the observed differences in inhibin processing. To test this hypothesis, we challenged LD and SD female hamsters with exogenous gonadotropins. While
\end{abstract}

both groups responded with increased inhibin expression, the effects were muted in ovaries of SD females and there was no evidence of ovulation in these animals. These data indicate that the ovaries of SD females are not immediately equipped to respond to gonadotropin stimulation. More generally, these data suggest that photoperiodic history affects ovarian inhibin production and secretion in response to gonadotropins.

Journal of Endocrinology (2002) 174, 85-94

\section{Introduction}

Much of our understanding regarding inhibin regulation relies on in situ hybridization studies in which the mRNAs for the individual inhibin subunits $\left(\alpha, \beta_{\mathrm{A}}\right.$, and $\left.\beta_{\mathrm{B}}\right)$ have been localized to individual follicles using sequencespecific probes (Meunier et al. 1988, Woodruff et al. 1988, Torney et al. 1989, Engelhardt et al. 1993, Fraser et al. 1993, Jih et al. 1993, Roberts et al. 1993, Garrett et al. 2000). It is clear that follicle-stimulating hormone (FSH) stimulates the synthesis of all three inhibin subunits in granulosa cells of antral follicles, and inhibits all three inhibin subunits in preovulatory follicles (Woodruff et al. 1987, 1989, Richards \& Hedin 1988, Meunier et al. 1989, Rivier et al. 1989, Woodruff \& Mayo 1990, Michel et al. 1991, Eramaa et al. 1994, Drummond et al. 2000). The mechanisms dictating the differential response of the genes to the actions of FSH are becoming more clear, especially for the $\alpha$-subunit. Specifically, FSH causes an increase in intracellular cAMP levels which leads to the phosphorylation of cAMP response element binding protein (CREB) and trancription via CREB-mediated interaction with a cAMP response element in the $\alpha$-promoter (Pei et al. 1991). Inhibin $\alpha$-subunit gene expression is repressed in preovulatory follicles by FSH-mediated induction of a CREB competitive inhibitor known as the inducible
cAMP early repressor (ICER) (Mukherjee et al. 1998). Regulation of the $\beta_{\mathrm{A}^{-}}$and $\beta_{\mathrm{B}^{-}}$-subunits is not as well understood, but FSH is clearly able to stimulate these subunits. However, the mechanism of stimulation seems to differ from that of the $\alpha$-subunit (Ardekani et al. 1998).

Equally important to the production of inhibin is the ability to assemble and process $\alpha-\beta_{\mathrm{A}}$ or $\alpha-\beta_{\mathrm{B}}$ dimers at appropriate times during the cycle. While not originally appreciated, it is now clear that the differential regulation of the $\beta$-subunits is critically important to the control of the normal reproductive cycle in polyovular as well as mono-ovular species (Fraser et al. 1995, Woodruff et al. 1996). Thus, the finding of differential compartmentalization of the mRNAs encoding the two $\beta$-subunits (companion paper Kenny et al. 2002) may be a first step towards an understanding of these mechanisms. Inhibin $A$ and inhibin $\mathrm{B}$ are synthesized as prohormones that are cleaved in order to release the biologically active C-termini of their constitutive $\alpha-$ and $\beta$-subunits (Mason et al. 1996). The processing and cleavage of inhibin is not understood in vivo or in vitro. In the companion paper, we demonstrate that both the quantity and kind of inhibin is reduced in Siberian hamster (Phodopus sungorus) ovaries when the animals are housed in short rather than long days (Kenny et al. 2002). Little or no mature, fully processed inhibin is detected in ovaries of females exposed to long day (LD) or 


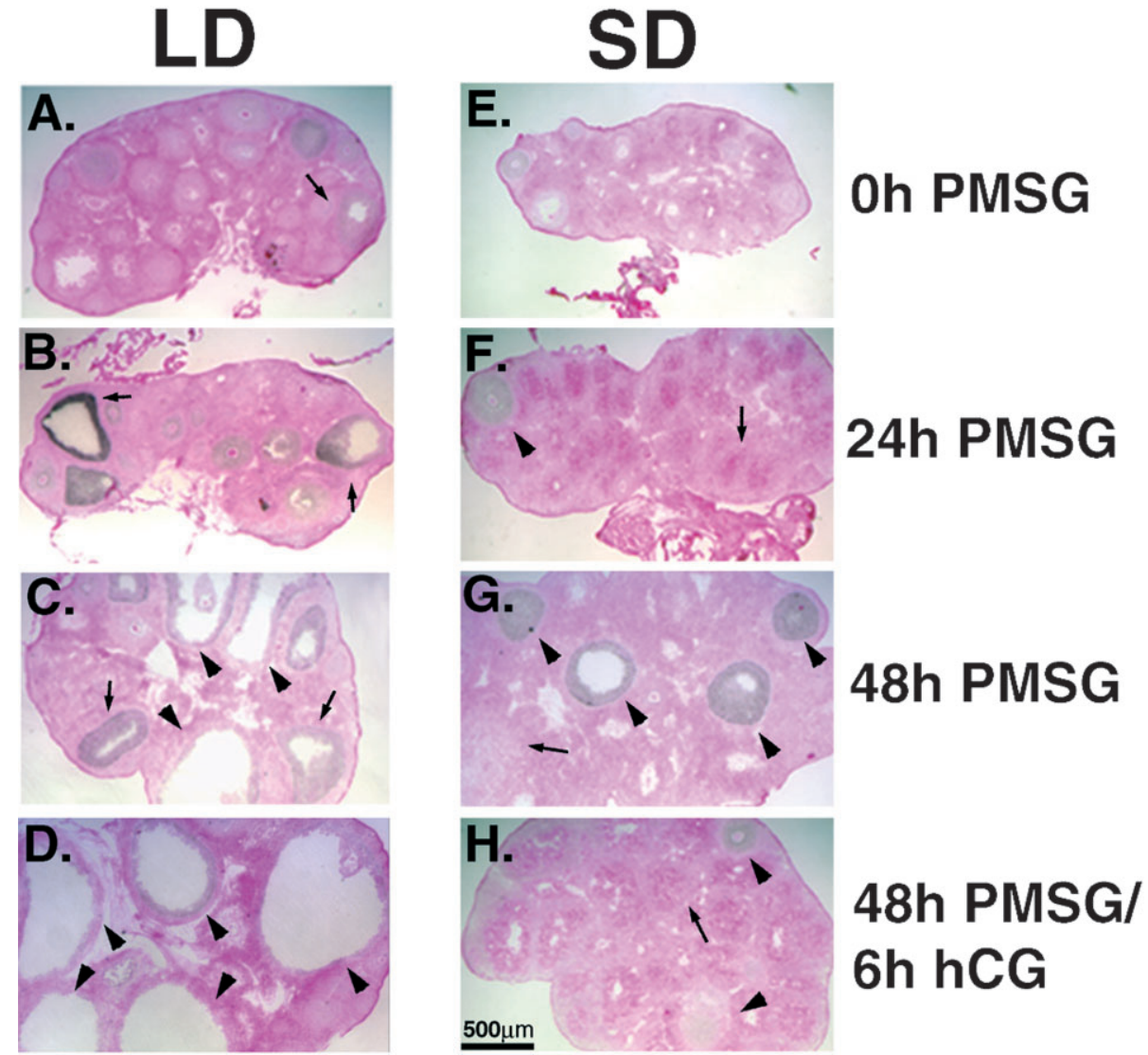

\begin{abstract}
Figure 1 In situ hybridization of inhibin $\alpha$-subunit mRNA in long day (LD) and short day (SD) PMSG- and hCG-stimulated ovaries. The bright-field images show sections from ovaries hybridized with antisense ${ }^{32} \mathrm{P}$-UTP-labeled riboprobes directed against inhibin $\alpha$-subunit. (A-D) $\alpha$-Subunit mRNA expression in LD PMSG- and hCG-stimulated ovaries. In the LD immature ovary, follicles of $410-520 \mu \mathrm{m}$ in diameter developed (arrow in A). In PMSG-stimulated LD hamsters, two follicle populations developed, follicles $>600 \mu \mathrm{m}$ in diameter (arrowheads in C and D) and follicles $350-590 \mu \mathrm{m}$ in diameter (thin arrows in B and C). (E-H) $\alpha$-Subunit mRNA expression in SD PMSGand hCG-stimulated ovaries. In the PMSG-stimulated SD hamsters, a single population of follicles, $340-560 \mu \mathrm{m}$ in diameter, was observed (arrowheads in F and G). Additionally, fewer follicles developed than in LD ovaries (arrowheads in $\mathrm{G}$ and $\mathrm{H}$ ), and morphological evidence of luteinization was apparent (thin arrows in $\mathrm{F}, \mathrm{G}$ and $\mathrm{H}$ ). The scale bar in panel $\mathrm{H}$ also applies to panels $\mathrm{A}-\mathrm{G}$.
\end{abstract}

short day (SD) photoperiods and the overall levels of unprocessed inhibin in the ovaries of SD females are approximately half of the unprocessed inhibin in ovaries of LD females. Inhibin synthesis is stimulated by FSH; however, it is not known whether FSH-dependent proteases that are used in the processing of the inhibin subunits are stimulated. FSH, but not luteinizing hormone (LH), is significantly higher in LD animals when compared with SD animals. Thus, the intent of this study was to investigate directly FSH stimulation of inhibin production and follicle development in Siberian hamsters housed under different photoperiods. Interestingly, FSH alone is not sufficient to induce full inhibin processing in SD hamsters, suggesting that additional environmental or hormonal cues are necessary to induce mature levels of inhibin production.

\section{Materials and Methods}

\section{Animals and experimental procedures}

Animals were housed as described in the companion paper (Kenny et al. 2002). Two animal groups were analyzed. Twenty-two-day-old, LD hamsters (exposed to $16 \mathrm{~h}$ light:8 h darkness) and 7-week-old SD hamsters (exposed to $6 \mathrm{~h}$ light: $18 \mathrm{~h}$ darkness) were injected with $5 \mathrm{IU}$ pregnant mare serum gonadotropin (PMSG) (Sigma, St Louis, MO, USA). Animals were then killed at $24 \mathrm{~h}$ or $48 \mathrm{~h}$ following injection. Additional groups of animals were injected with 5 IU human chorionic gonadotropin (hCG) (Sigma) $48 \mathrm{~h}$ after receiving PMSG, and were then killed $6 \mathrm{~h}, 12 \mathrm{~h}, 24 \mathrm{~h}$ and $48 \mathrm{~h}$ later. All animals were treated in accordance with the NIH Guide for the Care and Use of Laboratory Animals. 

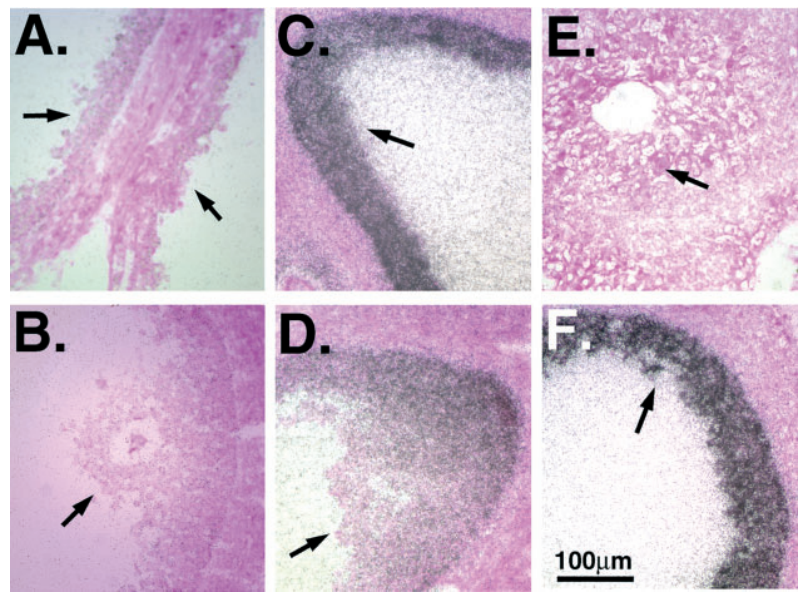

Figure 2 In situ hybridization of inhibin $\alpha$-subunit mRNA in LD large preovulatory follicles ( $>600 \mu \mathrm{m}$ in diameter), in LD and SD Graafian follicles (450-600 $\mu \mathrm{m}$ in diameter) and in SD luteinized granulosa cells. The bright-field images presented are higher magnification images illustrating follicles in Fig. 1C and G. (A-B) Lower inhibin $\alpha$-subunit mRNA expression levels were observed in the mural granulosa cells (arrows in A) and cumulus cells (arrow in B) in large preovulatory follicles found in LD PMSG-stimulated hamsters. (C-D) Higher inhibin $\alpha$-subunit mRNA expression levels were detected in mural (arrow in C) and cumulus cells (arrow in D) of Graafian follicles. (E-F) Luteinized tissue was detected after PMSG stimulation of short photoperiod hamsters (arrow in E), and high levels of inhibin $\alpha$-subunit mRNA were detected in granulosa cells of SD PMSG-stimulated follicles (arrow in F). The scale bar in panel $\mathrm{F}$ also applies to panels A-E.

In situ hybridization, protein extraction, Western blot analysis, and hormone assays

The in situ hybridization, protein extraction, Western blot analysis, and hormone assay procedures were conducted as described in the companion paper (Kenny et al. 2002).

\section{Statistical analyses}

Values are reported as means \pm S.E. Correlations between inhibin A and inhibin B levels in ovarian homogenates and serum of LD and SD PMSG- and hCG-treated hamsters were determined using simple linear regression analyses. In all cases $P<0 \cdot 05$ was considered significant. Paired comparisons were made using paired $t$-test.

\section{Results}

Regulation of follicle development in ovaries collected from PMSG-stimulated female Siberian hamsters housed under long and short days

LD and SD female Siberian hamsters were injected with PMSG (a source of FSH) to induce follicle maturation and hCG to induce ovulation and luteinization. PMSG stimulation caused an increase in follicle size in the ovaries of LD hamsters (Fig. 1A-C). Inhibin $\alpha$-subunit mRNA was detected in follicles $>250 \mu \mathrm{m}$ in diameter. Two populations of follicles developed as a consequence of PMSG stimulation in LD hamsters. Follicles greater than $600 \mu \mathrm{m}$ in diameter developed $48 \mathrm{~h}$ after PMSG stimulation (Fig. 1C). These follicles were designated large preovulatory follicles, and the inhibin $\alpha$-subunit was much less abundant in mural and cumulus cells of these follicles than in Graafian follicles (Fig. 2 A-D). The second population of follicles induced by PMSG was between 250 and $480 \mu \mathrm{m}$ in diameter. Inhibin $\alpha$-subunit expression was located throughout the granulosa cells of these follicles (Fig. 2C and D). As a consequence of an ovulatory dose of hCG, a further increase in follicle size was detected (Fig. 1D).

One population of follicles developed as a consequence of PMSG stimulation in the SD hamsters, and these follicles expressed $\alpha$-subunit uniformly throughout the granulosa cell layer. The ovaries of 7-week-old SD females contained follicles up to $420 \mu \mathrm{m}$ in diameter (Fig. 1E). Fewer follicles developed in the SD animals in response to PMSG when compared with the LD animals (Fig. 1B and F), although the inhibin $\alpha$-subunit mRNA was expressed at comparable levels in antral follicles of these animals (Fig. 2C and F). Morphological evidence of luteinization was apparent throughout the ovarian tissue after $24 \mathrm{~h}$ of PMSG treatment in the SD hamsters (Figs $1 \mathrm{~F}$ and 2E). Follicle size increased by $48 \mathrm{~h}$ of PMSG stimulation, but large preovulatory follicles were absent in the short photoperiod ovary (compare Fig. $1 \mathrm{G}$ with $1 \mathrm{C}$ ). After $48 \mathrm{~h}$ of PMSG stimulation and $6 \mathrm{~h}$ of hCG stimulation, most follicular granulosa cells had a distinctive luteinized morphology in the $\mathrm{SD}$ ovaries (Fig. 1H).

To determine if the $\beta_{\mathrm{A}}$-subunit was regulated in a similar fashion, adjacent ovarian sections from LD hamsters were hybridized to inhibin $\alpha$ - and $\beta_{\mathrm{A}}$-riboprobes. As was observed for the $\alpha$-subunit, the $\beta_{\mathrm{A}}$-subunit mRNA abundance was lower in the large preovulatory follicles than in follicles $<600 \mu \mathrm{m}$ in diameter (Fig. $3 \mathrm{H}$, I and J). Inhibin $\alpha$-subunit signal was greater than the $\beta_{\mathrm{A}}$-subunit in all size classes of the follicles of the 25-day-old hamster (Fig. 3A and F). PMSG stimulation caused an increase in follicle size and an increase in the expression of both inhibin subunits (Fig. 3B, C, G and $\mathrm{H}$ ). The consequence of an ovulatory dose of hCG on inhibin $\alpha$ - and $\beta_{\mathrm{A}^{-}}$subunit expression was also compared. A further increase in follicle size was detected after $48 \mathrm{~h}$ of PMSG stimulation and $6 \mathrm{~h}$ of hCG stimulation, and oocyte bridges were still intact in the follicles (Fig. 3D and I). By $12 \mathrm{~h}$ of hCG treatment inhibin subunit expression was decreased (Fig. $3 \mathrm{E}$ and J, Fig. 4B, D, F and H). Histologically, there was evidence of dispersion of cumulus cells (arrows, Fig. 4E and $G$ ) and the oocytes were found in the center of the follicle. By $12 \mathrm{~h}$ after injection of hCG corpora lutea were present (data not shown), indicating that ovulation had occurred. 

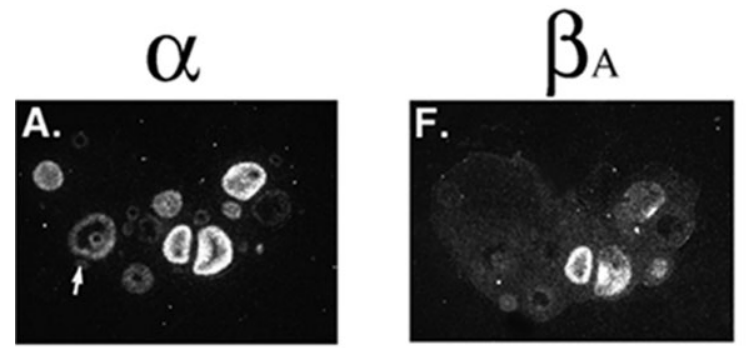

\section{Oh PMSG}
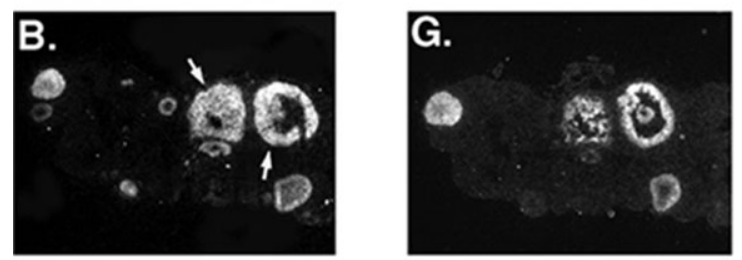

\section{4h PMSG}
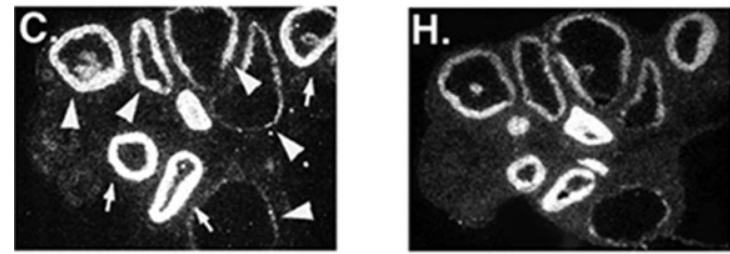

\section{8h PMSG}
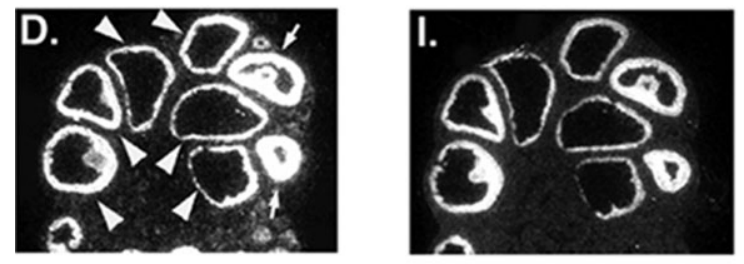

\section{8h PMSG/ 6h hCG}
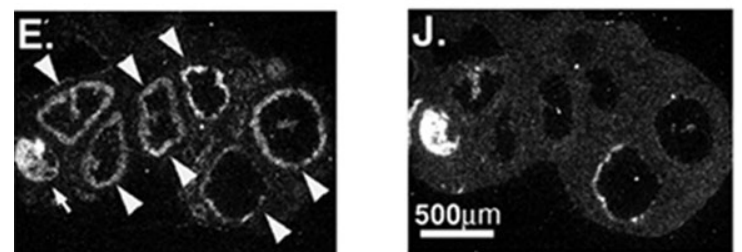

\section{8h PSMG/ 12h hCG}

Figure 3 In situ hybridization of inhibin $\alpha$-subunit and inhibin $\beta_{\mathrm{A}}$-subunit mRNA levels in adjacent ovarian sections of LD PMSG- and hCG-stimulated hamsters. The dark-field images presented in panels A-J show adjacent sections hybridized with antisense riboprobes directed against inhibin $\alpha$-subunit $(\mathrm{A}-\mathrm{E})$ or inhibin $\beta_{\mathrm{A}}$-subunit $(\mathrm{F}-\mathrm{J}$ ) respectively by in situ hybridization. The two follicle populations that developed are follicles $>600 \mu \mathrm{m}$ in diameter (arrowheads in C-E) and follicles 350-590 $\mu \mathrm{m}$ in diameter (thin arrows in A-E). The scale bar in panel $\mathrm{J}$ also applies to panels A-I.

Regulation of inhibin protein translation in ovaries from PMSG-stimulated Siberian hamsters

Production of the inhibin subunits was investigated in PMSG-stimulated LD and SD hamsters by protein blot analyses (Figs 5-7). The protein content of each lysate was measured and equal amounts of protein were loaded onto each gel.

Treatment with PMSG (24 h and $48 \mathrm{~h}$ ) and PMSG+ hCG $(48 \mathrm{~h} / 6 \mathrm{~h})$ stimulated the dominant precursor forms of dimeric inhibin in the ovaries of LD females (Fig. 5A, black arrowheads). The level of the precursor forms of dimeric inhibin decreased $12 \mathrm{~h}$ following hCG treatment. Mature dimeric inhibin $(\alpha \mathrm{C} / \beta)$ was detected at lower levels than the precursor forms as illustrated in the right hand blot of Figs 5A and 7A. Samples were reduced to determine the change in inhibin $\alpha_{-}, \beta_{\mathrm{A}^{-}}$and $\beta_{\mathrm{B}^{-}}$ subunit production in ovarian lysates in response to treatment (Fig. 5B-D). The inhibin $\alpha$-subunit was detected as three different forms, potentially a nonglycosylated, a monoglycosylated $(\alpha \mathrm{C})$ and a precursor protein $(\alpha \mathrm{N} \alpha \mathrm{C})$ (Fig. 5B). The same pattern as observed for the 
dimeric inhibin was also noted for all forms of the inhibin $\alpha$-subunit following PMSG treatment, with a further increase $6 \mathrm{~h}$ post hCG treatment and a decrease 24 and $48 \mathrm{~h}$ post hCG treatment (Fig. 5B).

The inhibin $\beta_{\mathrm{A}}$-subunit was detected as mature $\left(\beta_{\mathrm{A}}\right)$ and precursor proteins $\left(\operatorname{pro} \beta_{\mathrm{A}}\right)$, both of which showed a slight increase following 48-h PMSG treatment and a decrease following 12-h hCG treatment in ovaries of LD females (Fig. $5 \mathrm{C}$ ). The inhibin $\beta_{\mathrm{B}}$-subunit was detected as mature $\left(\beta_{\mathrm{B}}\right)$ and precursor proteins $\left(\right.$ pro $\left.\beta_{\mathrm{B}}\right)$ which showed a slight increase following PMSG (48 h) and PMSG/hCG $(48 \mathrm{~h} / 6 \mathrm{~h})$ and decreased following $12-\mathrm{h}$ hCG treatment (Fig. 5D). Mature $\beta_{\mathrm{A}^{-}}$and $\beta_{\mathrm{B}}$-subunit proteins were detected at time 0 in the absence of detectable mature $\alpha$-subunit $(\alpha \mathrm{C})$.

The patterns of protein production in the ovaries of SD females were different from those of LD females following PMSG/hCG stimulation. Dimeric inhibin, as well as $\alpha-$, $\beta_{\mathrm{A}^{-}}$and $\beta_{\mathrm{B}^{-}}$-subunits production increased $48 \mathrm{~h}$ after PMSG stimulation and decreased $12 \mathrm{~h}$ after hCG treatment in SD ovaries (Fig. 6A-D). Mature dimeric inhibin $(\alpha \mathrm{C} / \beta)$ was detected in LD unstimulated and $48-\mathrm{h}$ PMSG-stimulated hamster ovaries and in SD 48-h PMSG-stimulated hamster ovaries (Fig. 7A). A potential difference in glycosylation of the mature $\alpha$-subunit was observed in ovaries of LD and SD PMSG/hCG-treated hamsters (Fig. 7B). The $\alpha$-subunit was only detected as a higher molecular weight mature protein, a potentially glycosylated form $(\alpha \mathrm{C})$ and a precursor protein $(\alpha \mathrm{N} \alpha \mathrm{C})$ in the SD PMSG/hCG-stimulated hamster compared with the lower molecular weight protein, a potentially nonglycosylated form of the mature $\alpha$-subunit $(\alpha \mathrm{C})$ found in the LD PMSG/hCG-stimulated hamster (Fig. 7B). The ovary of the SD PMSG/hCG-stimulated hamsters produced more $\alpha$-subunit than the $\beta_{\mathrm{A}}$-and $\beta_{\mathrm{B}}$-subunits (Fig. $6 \mathrm{~B}-\mathrm{D}$ ). Dimeric inhibin levels and $\alpha$-subunit levels are higher in the ovarian lysates throughout the PMSG/hCG stimulation time course of LD hamsters than in SD hamsters (Fig. 7A and B).

Production of dimeric inhibin A and inhibin B were in ovarian extracts from LD and SD PMSG- and hCGtreated Siberian hamsters (Fig. 8A and B). In the LD hamsters, ovarian inhibin levels increased $24 \mathrm{~h}$ following PMSG treatment and continued to increase until both ligands were downregulated $6 \mathrm{~h}$ after hCG (Fig. 8A). Inhibin B levels were higher during PMSG stimulation. In the SD PMSG-stimulated hamsters, the concentration of ovarian inhibin was significantly lower than in the LD.

\section{Regulation of inhibin $A$ and $B$ secretion in PMSG-stimulated female Siberian hamsters}

Serum inhibin levels were measured from LD and SD PMSG- and hCG-treated Siberian hamsters (Fig. 8). In the LD hamsters, serum inhibin levels increased $24 \mathrm{~h}$ following PMSG treatment and continued to increase until both ligands were downregulated $12 \mathrm{~h}$ after hCG treatment (Fig. 8C). An increase in inhibin $\mathrm{B}$ alone was detected $24 \mathrm{~h}$ following hCG treatment at which time newly recruited follicles were detected (Fig. 8C). In the SD PMSG-stimulated hamster, the concentration of inhibin secreted in the serum was significantly lower than in the LD (Fig. 8D).

\section{Discussion}

The immediate goal of this study was to investigate how FSH regulates inhibin synthesis and secretion and, in turn, contributes to the overall regulation of the reproductive axis in Siberian hamsters. In order to examine the regulation of inhibin A and inhibin B during follicle development, female Siberian hamsters reared under LD or SD were stimulated with PMSG, and inhibin synthesis and secretion were measured. Our initial hypothesis proposed that a deficiency of FSH limited follicular growth in both immature LD females and photo-inhibited seven-week-old SD females. If the deficiency in FSH limited follicular development, then the ovaries from both groups of females should respond similarly to PMSG. FSH stimulates the production of gonadal inhibins which, in turn, feedback to the pituitary to inhibit FSH synthesis and secretion (Woodruff et al. 1996, Bernard et al. 2001). Because serum FSH levels are higher in LD than in SD hamsters as shown in the companion paper (Kenny et al. 2002), we hypothesized that inhibin may be differentially regulated in different photoperiods. Several important and novel observations were made including the ability of young (three-week-old), immature female hamsters reared in long day lengths to immediately respond to PMSG by synthesizing and secreting inhibin $A$ and inhibin B. Conversely, older Siberian hamsters in which reproductive maturation had been suppressed by exposure to short photoperiods do not secrete significant quantities of inhibin A or inhibin B following treatment with PMSG. Thus, FSH alone is not sufficient to stimulate a normal ovulatory cycle in SD animals.

PMSG-mediated follicle development in the immature LD Siberian hamster differed somewhat from follicle development in rats and mice stimulated with exogenous hormone (Parkening 1990, Jih et al. 1993, Hubbard \& Rojas 1994, O’Shaughnessy \& Gray 1995, Yaron et al. 1998). Specifically, one population of follicles developed quickly and did not sustain inhibin subunit expression after reaching a size averaging $600 \mu \mathrm{m}$. A second population grew steadily, reaching nearly $500 \mu \mathrm{m}$, and expressed the inhibin subunits throughout the granulosa cell layer. It is not clear why two populations of follicles, with apparently different growth rates and inhibin production were stimulated in response to FSH. In the SD animals, a large number of luteinized follicles were observed that did not express the inhibin subunits and only small follicles developed in response to hormone injection. In those 
$\alpha$
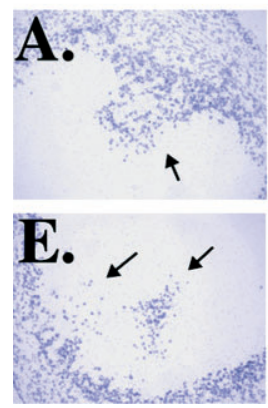

$\alpha$
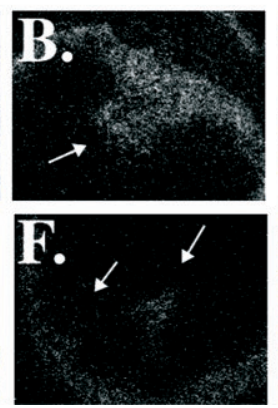

$\beta_{\mathrm{A}}$
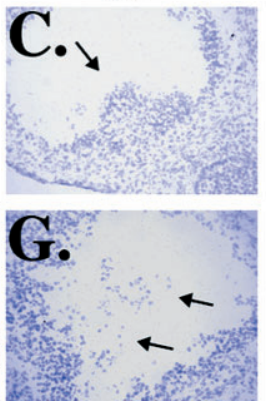
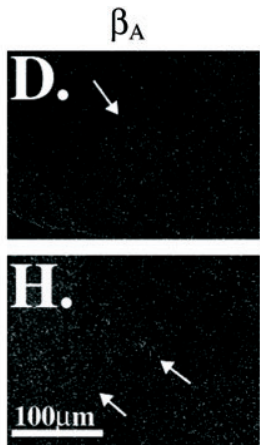

Figure 4 In situ hybridization of inhibin $\alpha$-subunit and $\beta_{\mathrm{A}}$-subunit mRNA in intact and dispersed cumulus cells of LD PMSG/hCG-stimulated hamsters. (A-H) The images presented are higher magnification images shown in bright-field (A, C, E and $G$ ) and dark-field (B, D, F and $\mathrm{H}$ ) illustrating follicles in Fig. $3 \mathrm{E}$ and J. Inhibin $\alpha$-subunit and $\beta_{\mathrm{A}}$-subunit signal in intact (arrows in A-D) and dispersed cumulus cells (arrows in $\mathrm{E}-\mathrm{H}$ ) were detected by in situ hybridization. The scale bar in panel $\mathrm{H}$ also applies to panels $\mathrm{A}-\mathrm{G}$.

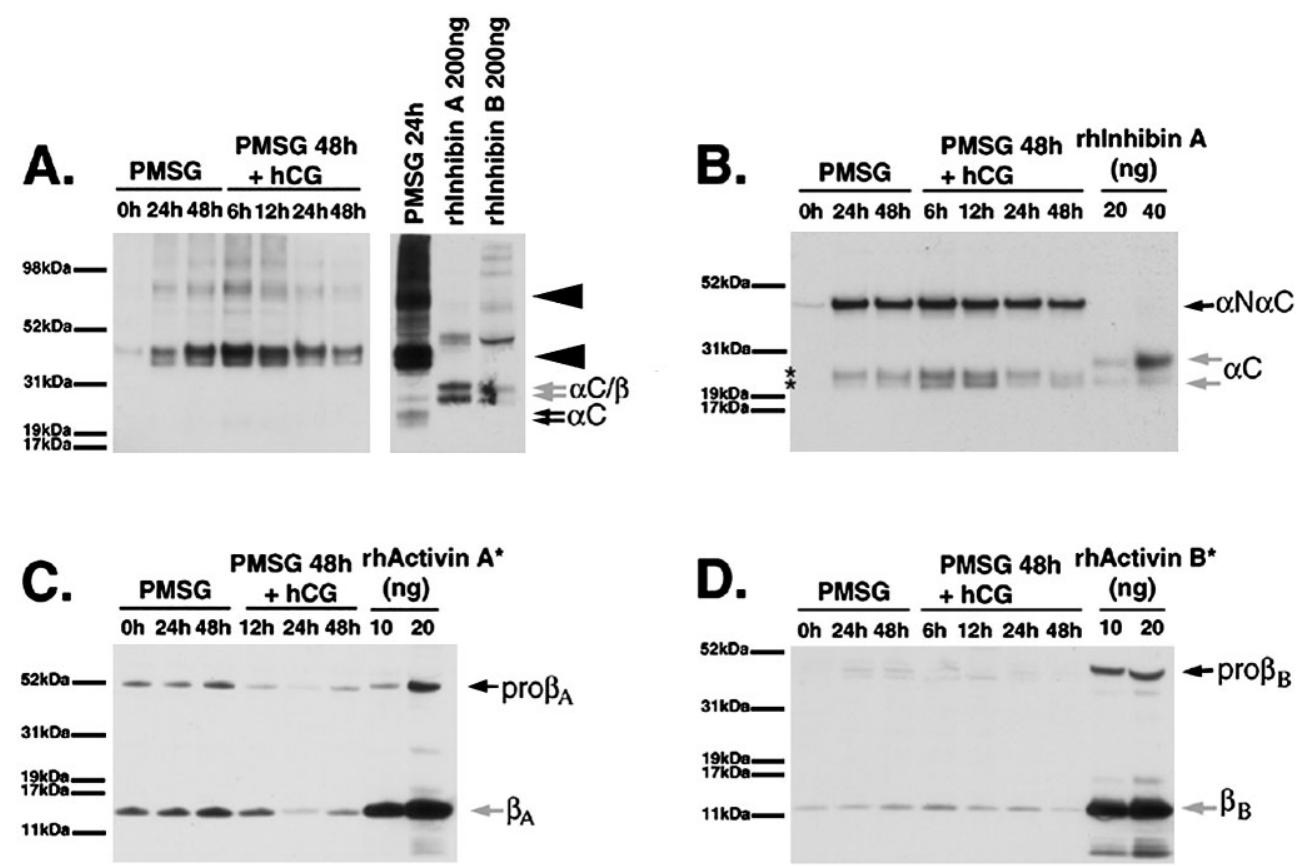

Figure 5 Western blot analysis of inhibin and inhibin $\alpha-, \beta_{\mathrm{A}^{-}}, \beta_{\mathrm{B}^{-}}$-subunits in ovarian lysates of LD PMSGand hCG-stimulated hamsters. Proteins were extracted from individual ovaries and $20 \mu \mathrm{g}$ (A, left blot; B-D) or $100 \mu \mathrm{g}$ (A, right blot) of protein were loaded in each well as described in Materials and Methods. (A) Immunoblot analysis of ovarian extracts under nonreducing conditions using the $\alpha$-subunit polyclonal antibody. Inhibin was detected as a mature dimer $(\alpha \mathrm{C} / \beta)$, mature $\alpha$-subunit $(\alpha \mathrm{C})$ and precursor proteins (arrowheads). The right hand blot in (A) was overexposed to illustrate the presence and low levels of mature dimeric inhibin $(\alpha C / \beta)$ in these LD PMSG-treated hamsters. The standards, rh-inhibinA and rh-inhibin $\mathrm{B}$, were detected as mature dimers and precursor proteins. (B) Immunoblot analysis of ovarian extracts under reducing conditions using the $\alpha$-subunit polyclonal antibody. Two mature forms ( $\alpha \mathrm{C}$ and asterisks) and a precursor form $(\alpha \mathrm{N} \alpha \mathrm{C})$ of the $\alpha$-subunit were detected. The standard, rh-inhibin $\mathrm{A}$, was detected as nonglycosylated, diglycosylated and precursor forms of the protein. (C) Immunoblot analysis of ovarian extracts under reducing conditions using the $\beta_{\mathrm{A}}$-subunit polyclonal antibody. Mature $\left(\beta_{\mathrm{A}}\right)$ and precursor forms $\left(\operatorname{pro} \beta_{\mathrm{A}}\right.$ ) of the $\beta_{\mathrm{A}}$-subunit were detected. Rh-activin A (asterisk; C) standard was detected as a mature and precursor protein of the inhibin $\beta_{A}$-subunit. The lowest band detected in the rh-activin $A$ standard was likely a degradation product. (D) Mature $\left(\beta_{\mathrm{B}}\right)$ and precursor forms $\left(\operatorname{pro} \beta_{\mathrm{B}}\right)$ of the $\beta_{\mathrm{B}}$-subunit were detected. Rh-activin B (asterisk; D) standard was detected as a mature and precursor protein of the inhibin $\beta_{\mathrm{B}}$-subunit. The lowest band detected in the rh-activin B standard was likely a degradation product. 

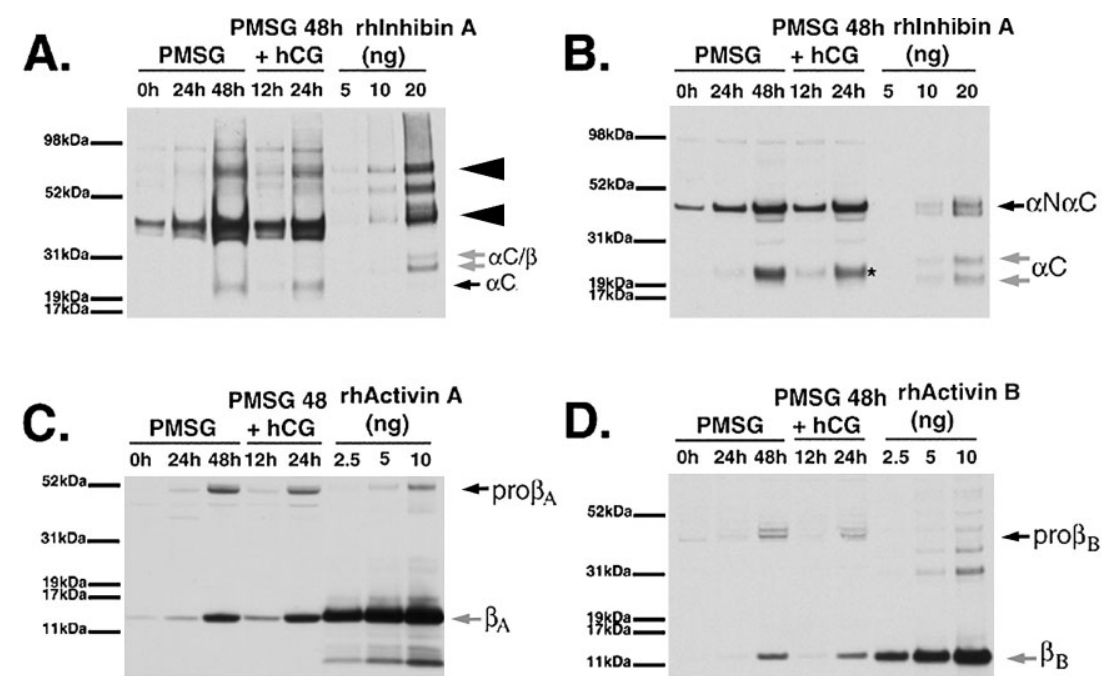

Figure 6 Western blot analysis of inhibin and inhibin $\alpha-, \beta_{A^{-}}, \beta_{B}$-subunits in ovarian lysates of SD PMSG- and hCG-stimulated hamsters. Proteins were extracted from individual ovaries and $30 \mu \mathrm{g}$ protein were loaded in each well. (A) Immunoblot analysis of ovarian extracts under nonreducing conditions using the $\alpha$-subunit polyclonal antibody. Inhibin was detected in its mature $\alpha$-subunit form $(\alpha \mathrm{C})$ and dominant precursor forms (arrowheads). The standard, rh-inhibin $\mathrm{A}$, was detected as a mature dimer $(\alpha \mathrm{C} / \beta)$ and in precursor forms (arrowheads). (B) Immunoblot analysis of ovarian extracts under reducing conditions using the $\alpha$-subunit polyclonal antibody. A mature ( $\alpha \mathrm{C}$ and asterisk) and precursor form of the $\alpha$-subunit were detected $(\alpha \mathrm{N} \alpha \mathrm{C})$. The standard, rh-inhibin $\mathrm{A}$, was detected in its nonglycosylated, diglycosylated and precursor forms. (C) Immunoblot analysis of ovarian extracts under reducing conditions using the $\beta_{\mathrm{A}}$-subunit polyclonal antibody. Mature $\left(\beta_{\mathrm{A}}\right)$ and precursor forms $\left(\right.$ pro $\beta_{\mathrm{A}}$ ) of the $\beta_{\mathrm{A}}$-subunit were detected. Rh-activin A standard was detected as a mature and precursor protein of the inhibin $\beta_{A^{A}}$-subunit. The lowest band detected in the rh-activin A standard was likely a degradation product. (D) Mature $\left(\beta_{B}\right)$ and precursor forms $\left(\right.$ pro $\beta_{\mathrm{B}}$ ) of the $\beta_{\mathrm{B}}$-subunit were detected. Rh-activin B standard was detected as a mature and precursor protein of the inhibin $\beta_{B}$-subunit.

follicles that did respond to PMSG by granulosa cell proliferation, the inhibin subunits were stimulated in a pattern consistent with LD follicles. The differential response of the ovaries to FSH in terms of follicle selection and granulosa cell proliferation was not anticipated and will be further investigated in future studies.

Little inhibin dimer or free $\alpha$-subunit is detected in ovarian homogenates of 25 -day-old LD females. At the same time, both the $\beta_{\mathrm{A}^{-}}$and $\beta_{\mathrm{B}}$-subunits are detected suggesting that the immature ovary is capable of producing activin $A$, activin $A B$, or activin $B$ but not inhibins. Twenty-four hours after PMSG stimulation, inhibin $\alpha$-subunit is induced and dimeric inhibin is detected. The $\beta$-subunits are not significantly induced by PMSG. Thus, the ovary may go from a relatively activin dominated environment to an inhibin dominated environment. Assays that recognize the various forms of activin in ovarian homogenates will clarify whether these subunits are, in fact, assembled into bioactive ligands.

The major form of inhibin that is detected in ovarian lysates from $\mathrm{LD}$ females is the pro- $\alpha \mathrm{C} / \beta$ form. Little or no mature inhibin, i.e. $\alpha \mathrm{C} / \beta$, is detected in the ovarian lysates unless large amounts of protein are analyzed. Even under these conditions, the mature dimer does not accumulate to any appreciable level within the ovary. Thus, it is possible that the mature form is secreted immediately from the ovary in LD animals. Consistent with this prediction is our ability to detect rising levels of inhibin A and inhibin $\mathrm{B}$ in the peripheral circulation following PMSG stimulation. Moreover, the serum levels of these hormones fall following 6-12 hours of hCG stimulation, consistent with the observed declines in subunit mRNA levels.

To determine whether FSH is the only agonist necessary to stimulate inhibin secretion from the ovary, SD animals were challenged with PMSG. SD and LD animals were raised until weaning on normal long-day conditions. At three weeks of age SD animals were exposed to inhibitory short photoperiods for five weeks. Thus LD and SD animals had the opportunity to develop similarly through weaning. The exposure to short days inhibits further reproductive maturation. Interestingly, a single form of the $\alpha$-subunit, but neither $\beta$-subunit, was detected in ovarian lysates from SD females. Upon hormone stimulation, all three subunits were induced; however, little inhibin A or inhibin B was detected in serum samples. 

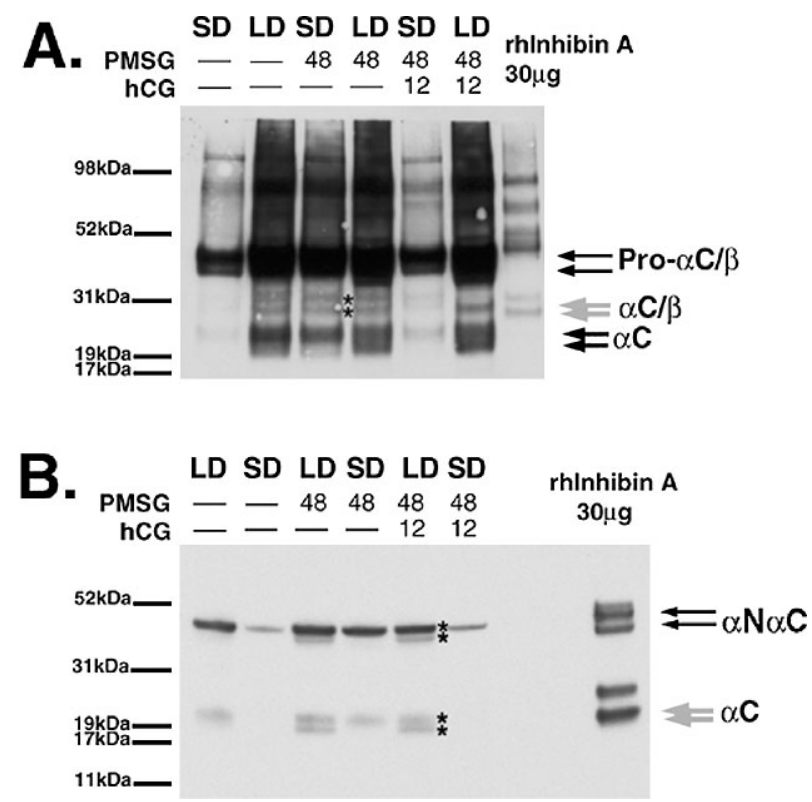

Figure 7 Western blot analysis directly comparing inhibin and inhibin $\alpha$-subunit production in the ovaries of LD and SD PMSGand hCG-stimulated hamsters. (A) Immunoblot analysis of ovarian extract under nonreducing conditions using the $\alpha$-subunit polyclonal antibody. Inhibin was detected as a mature dimer $(\alpha \mathrm{C} / \beta$ and asterisks), a mature $\alpha$-subunit $(\alpha \mathrm{C})$ and in precursor forms. This blot was overexposed to illustrate the presence and low levels of mature dimeric inhibin in these PMSG/hCG-treated hamsters. The standard, rh-inhibin $\mathrm{A}$, was detected as a mature dimer $(\alpha \mathrm{C} / \beta)$ and its precursor forms. (B) Immunoblot analysis of ovarian extracts under reducing conditions using the $\alpha$-subunit polyclonal antibody. Two mature forms $(\alpha \mathrm{C})$ and a precursor form $(\alpha \mathrm{N} \alpha \mathrm{C})$ of the $\alpha$-subunit were detected (asterisks). The standard, rh-inhibin A, was detected in its nonglycosylated, diglycosylated and precursor forms.

Thus, although the subunits were induced by FSH, the processing and secretion of dimeric inhibins was quantitatively, if not qualitatively, different from that observed in LD animals. It is possible that the ovaries were less sensitive to FSH; however, when directly compared, the abundance of pro- $\alpha \mathrm{C} / \beta$ was similar in both sets of animals 48 hours following PMSG treatment. This suggests that some other factor is necessary to regulate the final stages of processing and secretion of mature inhibin in the $\mathrm{SD}$ females. These results also suggest that exposure to short days does not simply result in the arrest of ovarian development, but may cause significant changes in endocrine signaling mechanisms within the ovary.

To examine whether the follicles stimulated by PMSG in LD and SD hamsters were able to respond to hCG two endpoints were examined: presence of corpora lutea (CL) and down-regulation of inhibin subunit mRNA and protein. Luteal tissue was detected in the hCG-treated ovaries of LD animals and inhibin subunit transcription was transiently stimulated and then suppressed. Serum levels of inhibin A and inhibin B fall following 6-12 hours of hCG stimulation, consistent with the observed decline in subunit mRNA levels in LD animals. No CL were detected in SD animals, but extensive luteinization of the granulosa cells was detected. Little change in inhibin biosynthesis or secretion was detected in response to hCG in SD animals. These results suggest that the SD granulosa cell is sensitive to hCG and can become luteinized; however, despite the growth of follicles up to $400 \mu \mathrm{m}$ these follicles are not able to undergo the processes leading to ovulation. These results confirm our conclusion that factors in addition to the gonadotropins are necessary to stimulate follicle development in the SD hamster.

One of the interesting findings from this study is the rise of inhibin A prior to inhibin $\mathrm{B}$ in response to the initial dose of PMSG, followed by an increase in inhibin B at 24 hours of PMSG plus hCG treatment in LD hamsters. The precise site of inhibin B synthesis has not been determined; however, this study suggests that the follicles that initially respond to FSH and that will ovulate produce inhibin A. Once the follicle population has been primed, inhibin B is produced in excess of inhibin A and likely represents secretion from follicles that will be selected in the subsequent cycle. The biosynthesis of inhibin $\mathrm{A}$ and inhibin B is highly regulated and one feature of the follicles that are present in the immature ovary is that they are not yet capable of inhibin B secretion.

While a number of rodent species, including the Siberian hamster (Phodopus sungorus) and the Syrian hamster (Mesocricetus auratus), have photoperiod-regulated reproductive function, the regulation of reproductive activity in the Siberian hamster is particularly interesting due to variations in its response to other environmental cues. For example, the presence of an opposite sex partner can alter reproductive function in the female Siberian hamsters. In the absence of a male, the female Siberian hamster does not have normal estrous cycles (Finley et al. 1995, Debeljuk et al. 1995). When a male is introduced to the environment, the female responds by initiating and maintaining successive estrous cycles (Finley et al. 1995, Murray \& Laprise 1995, Debeljuk et al. 1995, McMillan \& Wynne-Edwards 1999). More intriguingly, the average litter size of the Siberian hamster is five and it has been reported that these animals cannot be superovulated with PMSG (Parkening 1990, Parkening \& Collins 1991, Murray \& Laprise 1995). We did not count the number of oocytes present in the oviduct in the present study, but it was clear that the granulosa cells luteinized in response to hCG but not in response to ovulation. Thus, even in follicles that began the process of development, they were not able to respond to the normal cues of FSH and hCG. Therefore, some other factor must contribute not only to inhibin assembly and secretion but to the process of follicle maturation in this species. These factors may include a pheromone through the introduction of a male, repeat injections of $\mathrm{FSH}$, or some other factor. 


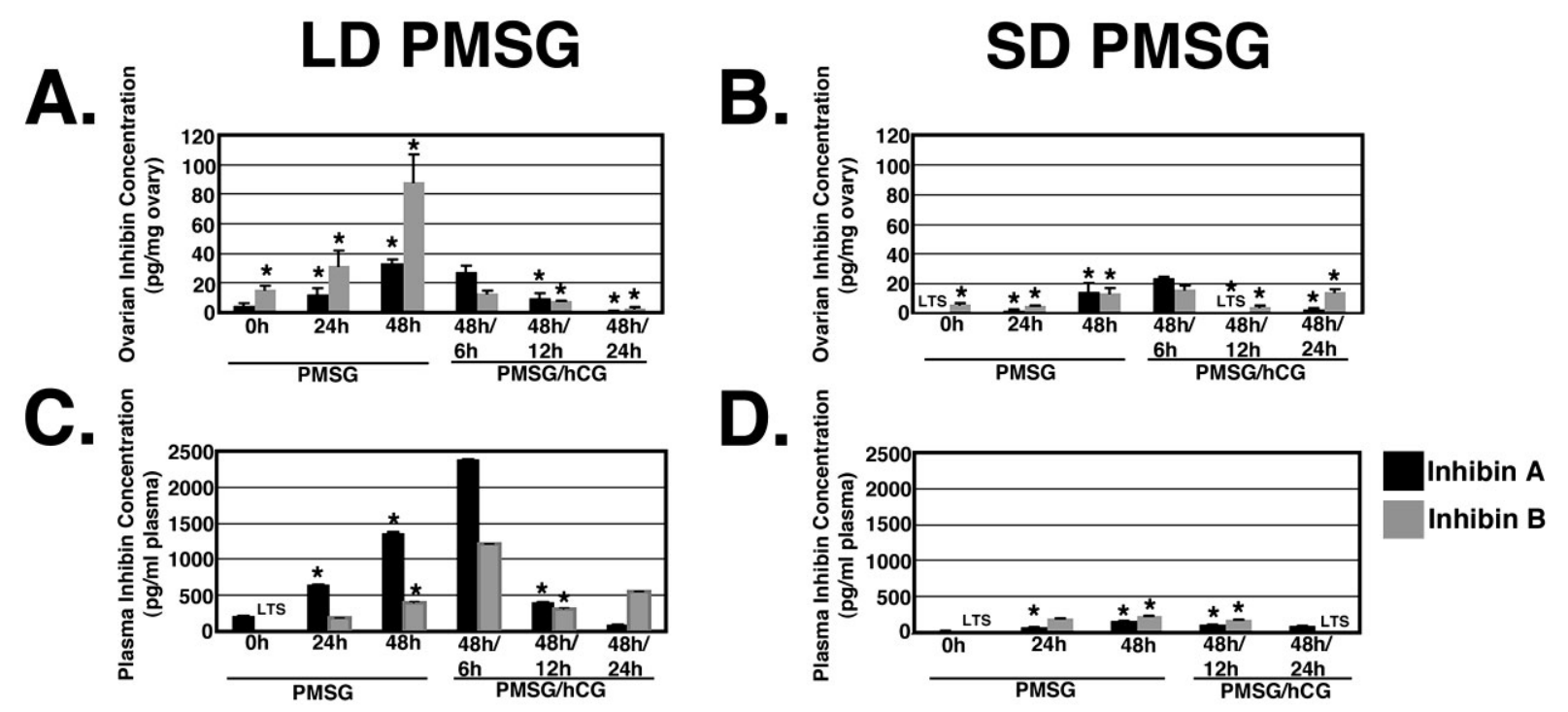

Figure 8 Measurement of ovarian and plasma inhibin A and inhibin B content by ELISA. Inhibin A and inhibin B ovarian concentration in the LD (A) and SD (B) PMSG- and hCG-stimulated hamsters and circulating concentrations in the LD (C) and SD (D) PMSG- and hCG-stimulated hamsters are shown. Significant differences in inhibin A and inhibin B between LD and SD PMSG- and hCG-stimulated hamster groups are indicated $\left(\mathrm{A}-\mathrm{D},{ }^{*} \mathrm{P}<0 \cdot 05\right)$.

In the wild, there are a number of additional cues that may come into play to allow resumption of normal ovulatory cycles. The presence of a male may impact the female reproductive tract in a way that had not previously been observed. Alternatively, the slow and steady rise of FSH following stimulation with long days (Kelly et al. 1994, Meredith et al. 1998, Bernard et al. 2000) may have the effect of priming the ovary by stimulating the expression of a number of factors including inhibin processing enzymes that may be necessary for normal follicle development. The steady state levels of the FSH receptor has not been investigated in the ovaries of long and short photoperiod Siberian hamsters, so the photoperiod differences observed here may reflect differential sensitivity of the ovary to PMSG (FSH). We do not favor this conclusion since inhibin mRNA can be synthesized in response to FSH. The results suggest that the ovaries of SD hamsters are not merely in an immature stage - rather, the follicles are somehow made resistant to the stimulation of an FSH surge. It is possible that this is necessary for the life history strategies of hamsters in the wild. For example, the animal must receive both a cue to stimulate follicle maturation and have available a male in the environment with whom to mate. In this manner, the ovary does not lose germ cell potential in useless ovulatory cycles.

In conclusion, the results of the current studies indicate that basal inhibin expression is photoperiod-dependent and that daylength regulates the ovary's responsiveness to exogenous gonadotropins. Future studies will investigate the additional factors which are necessary to regulate follicle development and inhibin biosynthesis in the SD animal. Further, it will be important to explore whether the mechanisms involved in making an SD ovarian follicle competent to respond to FSH are conserved in non-photoperiodic species.

\section{Acknowledgements}

The authors wish to thank Dr Neena B Schwartz who examined the histology of short photoperiod PMSG/ hCG-stimulated ovaries; Dr Wylie Vale who provided the inhibin subunit antibodies; Brigitte Mann who conducted the gonadotropin RIAs; Magdalena Suszko who provided the rh-activin A and rh-activin B conditioned media; and Stephanie Pangas who provided the purified rh-inhibin A and rh-inhibin B. This study was supported by NIH grant HD-21921, HD-37096 and HD-28048. H A Kenny is a fellow of the Training Program in Reproductive Biology (HD00768). D J Bernard is a Lalor Foundation Postdoctoral Fellow.

\section{References}

Ardekani AM, Romanelli JCD \& Mayo KE 1998 Structure of the rat inhibin and activin $\beta_{\mathrm{A}}$-subunit gene and regulation in an ovarian granulosa cell line. Endocrinology 139 3271-3279.

Bernard DJ, Merzlyak IY, Horton TK \& Turek FW 2000 Differential regulation of pituitary gonadotropin subunit messenger ribonucleic acid levels in photostimulated Siberian hamsters. Biology of Reproduction 62 155-161.

Bernard DJ, Chapman SC \& Woodruff TK 2001 Mechanisms of inhibin signal transduction. Recent Progress in Hormone Research 56 $417-450$. 
Debeljuk L, Rao JN \& Bartke A 1995 Developmental changes of tachykinins in the hypothalamus and anterior pituitary of female Siberian hamsters from prepuberty to adulthood. Peptides 16 827-831.

Drummond AE, Dyson M, Thean E, Groome NP, Robertson DM \& Findlay JK 2000 Temporal and hormonal regulation of inhibin protein and subunit mRNA expression by post-natal and immature rat ovaries. Journal of Endocrinology 166 339-354.

Engelhardt H, Smith KB, McNeilly AS \& Baird DT 1993 Expression of messenger ribonucleic acid for inhibin subunits and ovarian secretion of inhibin and estradiol at various stages of the sheep estrous cycle. Biology of Reproduction 49 281-294.

Eramaa M, Tuuri T, Hilden K \& Ritvos O 1994 Regulation of inhibin alpha- and beta A-subunit messenger ribonucleic acid levels by chorionic gonadotropin and recombinant follicle-stimulating hormone in cultured human granulosa-luteal cells. Journal of Clinical Endocrinology and Metabolism 79 1670-1677.

Finley CM, Gorman MR, Tuthill CR \& Zucker I 1995 Long-term reproductive effects of a single long day in the Siberian hamster (Phodopus sungorus). Journal of Biological Rhythms 10 33-41.

Fraser HM, Lunn SF, Cowen GM \& Saunders PT 1993 Localization of inhibin/activin subunit mRNAs during the luteal phase in the primate ovary. Journal of Molecular Endocrinology 10 245-257.

Fraser HM, Lunn S, Whitelaw PF \& Hillier SG 1995 Induced luteal regression: differential effects on follicular and luteal/activin subunit mRNAs in the marmoset monkey. Journal of Endocrinology 144 201-208.

Garrett WM, Mack SO, Rohan RM \& Guthrie HD 2000 In situ analysis of the changes in expression of ovarian inhibin subunit mRNAs during follicle recruitment after ovulation in pigs. Journal of Reproduction and Fertility 118 235-242.

Hubbard GM \& Rojas FJ 1994 Stimulation of ovarian adenlyl cyclase activity by gonadotroph: the natural and gonadotrophin-induced cycles in the hamster. Human Reproduction 9 2247-2254.

Jih MH, Lu JK, Wan YJ \& Wu TC 1993 Inhibin subunit gene expression and distribution in the ovaries of immature, young adult, middle-aged, and old female rats. Endocrinology 132 319-326.

Kelly KK, Goldman BD \& Zucker I 1994 Gonadal growth and hormone concentrations in photoregressed Siberian hamsters: pinealectomy versus photostimulation. Biology of Reproduction $\mathbf{5 1}$ 1046-1050.

Kenny HA, Bernard DJ, Horton TH \& Woodruff TK 2002 Photoperiod-dependent regulation of inhibin in Siberian hamsters: I. Ovarian inhibin production and secretion. Journal of Endocrinology 174 71-83.

McMillan HJ \& Wynne-Edwards KE 1999 Divergent reproductive endocrinology of the estrous cycle and pregnancy in dwarf hamsters (Phodopus). Comparative Biochemistry and Physiology 124 $53-67$.

Mason AJ, Farnworth PG \& Sullivan J 1996 Characterization and determination of the biological activities of noncleavable high molecular weight forms of inhibin A and activin A. Molecular Endocrinology 12 1055-1065.

Meredith JM, Turek FW \& Levine JE 1998 Effects of gonadotropinreleasing hormone pulse frequency modulation on the reproductive axis of photoinhibited male Siberian hamsters. Biology of Reproduction 59 813-819.

Meunier H, Cajander SB, Roberts VJ, Rivier C, Sawchenko PE, Hsueh AJ \& Vale W 1988 Rapid changes in the expression of inhibin alpha-, beta A-, and beta B-subunits in ovarian cell types during the rat estrous cycle. Molecular Endocrinology 2 1352-1363.

Meunier H, Roberts VJ, Sawchenko PE, Cajander SB, Hsueh AJ \& Vale W 1989 Periovulatory changes in the expression of inhibin alpha-, beta A-, and beta B-subunits in hormonally induced immature female rats. Molecular Endocrinology 3 2062-2069.
Michel U, Krozowski Z, McMaster J, Yu JH \& Findley JK 1991 The biphasic modulation of inhibin mRNA levels and secretion by PMSG in rat granulosa cells in vitro. Reproduction, Fertility, and Development 3 215-226.

Mukherjee A, Urban J, Sassons-Corsi P \& Mayo KE 1998 Gonadotropins regulate inducible cyclic adenosine $3^{\prime}, 5^{\prime}$ monophosphate early repressor in the rat ovary: implications for inhibin alpha subunit gene expression. Molecular Endocrinology 12 785-800.

Murray MK \& Laprise SL 1995 Ovulated oocytes collected from PMSG/hCG-treated and cycling Djungarian or Siberian hamsters (Phodopus sungorus) are structurally similar with no evidence of polar body formation, indicating arrest in meiosis I. Molecular Reproduction and Development $\mathbf{4 1}$ 76-83.

O'Shaughnessy PJ \& Gray SA 1995 Gonadotropin-dependent and gonadotropin-independent development of inhibin subunit messenger ribonucleic acid level in the mouse ovary. Endocrinology $1362060-2065$.

Parkening TA 1990 In vitro fertilization of Siberian hamster oocytes. Journal of Experimental Zoology 254 305-312.

Parkening TA \& Collins TJ 1991 Reproduction, pregnancy, and circulating reproductive hormones in the lactating Siberian hamster (Phodopus sungorus). Journal of Experimental Zoology 257 401-407.

Pei L, Dodson R, Schoderbek WE, Maurer RA \& Mayo KE 1991 Regulation of the alpha inhibin gene by cyclic adenosine $3^{\prime}, 5^{\prime}$-monophospate after transfection into granulosa cells. Molecular Endocinology 5 521-534.

Richards JS \& Hedin L 1988 Molecular aspects of hormone action in ovarian follicular development, ovulation and luteinization. Annual Review of Physiology 50 441-463.

Rivier C, Roberts V \& Vale W 1989 Possible role of luteinizing hormone and follicle-stimulating hormone in modulating inhibin secretion and expression during the estrous cycle of the rat. Endocrinology 125 876-882.

Roberts VJ, Barth S, El-Roeiy A \& Yen SS 1993 Expression of inhibin/activin subunits and follistatin messenger ribonucleic acids and proteins in ovarian follicles and corpus luteum during human menstrual cycle. Journal of Clinical Endocrinology and Metabolism 77 1402-1410.

Torney AH, Hodgson YM, Forage R \& de Kretser DM 1989 Cellular localization of inhibin mRNA in bovine ovary by in situ hybridization. Journal of Reproduction and Fertility 86 391-399.

Woodruff TK \& Mayo KE 1990 Regulation of inhibin synthesis in the rat ovary. Annual Review of Physiology 52 807-821.

Woodruff TK, Meunier H, Jones PBC, Hsueh AWJ \& Mayo KE 1987 Rat inhibin: molecular cloning of $\alpha$ - and $\beta$-subunit complimentary DNAs and expression in the ovary. Molecular Endocrinology 1 561-568.

Woodruff TK, D’Agostino J, Schwartz NB \& Mayo KE 1988 Dynamic changes in inhibin messenger RNAs in rat ovarian follicles during the reproductive cycle. Science 239 1296-1299.

Woodruff TK, D'Agostino JB, Schwartz NB \& Mayo KE 1989 Decreased inhibin gene expression in preovulatory follicles requires primary gonadotropin surges. Endocrinology 124 2193-2199.

Woodruff TK, Besecke LM, Groome N, Draper LB, Schwartz NB \& Weiss J 1996 Inhibin A and inhibin B are inversely correlated to follicle-stimulating hormone, yet are discordant during the follicular phase of the rat estrous cycle, and inhibin A is expressed in a sexually dimorphic manner. Endocrinology 137 5463-5467.

Yaron Y, Schwartz D, Evans MI, Lessing JB \& Rotter V 1998 Alternatively spliced mRNA transcripts encoding the extracellular domain of the FSH receptor gene. Expression in the mouse ovary during the ovulatory cycle. Journal of Reproductive Medicine $\mathbf{4 3}$ $435-438$.

Received in final form 8 March 2002

Accepted 5 April 2002 